\title{
Heart failure and atrial fibrillation: current concepts and controversies
}

\author{
Maarten P Van Den Berg, Anton E Tuinenburg, Harry J G M Crijns, \\ Isabelle C Van Gelder, A T Marcel Gosselink, Kong I Lie
}

\begin{abstract}
Summary
Heart failure and atrial fibrillation are very common, particularly in the elderly. Owing to common risk factors both disorders are often present in the same patient. In addition, there is increasing evidence of a complex, reciprocal relation between heart failure and atrial fibrillation. Thus heart failure may cause atrial fibrillation, with electromechanical feedback and neurohumoral activation playing an important mediating role. In addition, atrial fibrillation may promote heart failure; in particular, when there is an uncontrolled ventricular rate, tachycardiomyopathy may develop and thereby heart failure. Eventually, a vicious circle between heart failure and atrial fibrillation may form, in which neurohumoral activation and subtle derangement of rate control are involved. Treatment should aim at unloading of the heart, adequate control of ventricular rate, and correction of neurohumoral activation. Angiotensin converting enzyme inhibitors may help to achieve these goals. Treatment should also include an attempt to restore sinus rhythm through electrical cardioversion, though appropriate timing of cardioversion is difficult. His bundle ablation may be used to achieve adequate rate control in drug refractory cases.
\end{abstract}

(Heart 1997;77:309-313)

Department of Cardiology,

Thoraxcenter,

University Hospital

Groningen,

Groningen, The

Netherlands

M P Van Den Berg

A E Tuinenburg

H J G M Crijns

I C Van Gelder

A T Marcel Gosselink

$\mathrm{K}$ I Lie

Correspondence to

Dr Maarten P Van Den

Berg, Department of

Cardiology, Thoraxcente

University Hospital

Groningen, 9700 RB,

PO Box 30.001, Groningen,

The Netherlands.

Accepted for publication

13 August 1996

\section{Keywords: heart failure; atrial fibrillation}

Congestive heart failure is a large epidemiological problem, particularly in the elderly. The same is true for atrial fibrillation. These two disorders profoundly limit life expectancy. Another important epidemiological feature is that both conditions are often present in the same patient. This is partly due to the fact that heart failure and atrial fibrillation share important risk factors. In addition, a causal, reciprocal relation exists between heart failure and atrial fibrillation. Relevant epidemiological aspects as well as pathophysiological and clinical aspects of this interplay between heart failure and atrial fibrillation are reviewed.

\section{Epidemiological aspects}

The Framingham Study estimated the mean prevalence of heart failure to be approximately $1 \%$ in its local population. ${ }^{1}$ The prevalence of heart failure rose sharply with age; it doubled every decade, exceeding $10 \%$ in patients older than 80 years. Based on the number of hospitalisations, the prevalence of heart failure appears to increase over time. The epidemiological significance of heart failure is reflected in its profound adverse effect on prognosis, especially in severe cases. In the Framingham Study, one year mortality was $43 \%$ and five year mortality $75 \%$.

The Framingham Study has also provided insight into the epidemiology of atrial fibrillation; the overall chance that subjects 30 to 62 years old in the Framingham population would develop atrial fibrillation during 22 years of follow up was $2 \% .{ }^{2}$ However, the incidence was strikingly age dependent, older age (>55 years) conferring a greater than 3\% chance of developing atrial fibrillation. Unfortunately, there are as yet no reliable data as to whether the epidemiology of atrial fibrillation is changing, whether it is becoming more common, though this would seem likely given the fact that the number of elderly people is increasing. The prognostic implications of atrial fibrillation are grave. In the Framingham Study, development of atrial fibrillation was associated with a relative risk of 1.8 for overall mortality and 2.7 for cardiovascular mortality compared with subjects with sinus rhythm. The average time to death was six years.

HEART FAILURE AND ATRIAL FIBRILLATION

From an epidemiological point of view, a strong association exists between heart failure and atrial fibrillation. Whereas atrial fibrillation is relatively rare in mild heart failure, it is a common concomitant disorder in patients with more advanced disease (table 1) ${ }^{3-6}$ In one small study, as many as $35 \%$ of the patients with heart failure were reported to have concomitant atrial fibrillation. ${ }^{7}$ The impact of atrial fibrillation on mortality in patients with heart failure is controversial. In the largest study, combining data from V-HeFT I and II (Vasodilator Heart Failure Trial), no effect of atrial fibrillation on mortality was demonstra- 
Table 1 Studies of atrial fibrillation in heart failure with more than 200 patients

\begin{tabular}{lclll}
\hline Reference & $\begin{array}{l}\text { No of } \\
\text { patients }\end{array}$ & $\begin{array}{l}\text { Mean } \\
\text { LVEF } \\
(\%)\end{array}$ & $\begin{array}{l}A F \\
(\%)\end{array}$ & $\begin{array}{l}\text { Impact on } \\
\text { mortality }\end{array}$ \\
\hline Likoff $e t a l^{3}$ & 201 & 20 & 18 & None \\
Keogh $e t$ al $^{4}$ & 232 & 16 & NA & None \\
Middlekauff $e t a l^{5}$ & 395 & 19 & 19 & Increased \\
Carson $e t a l^{6}$ & 1427 & 30 & 14 & None \\
\hline
\end{tabular}

$\mathrm{AF}$, atrial fibrillation; LVEF, left ventricular ejection fraction $\mathrm{NA}$, not available.

ble. ${ }^{6}$ Conversely, heart failure is a common finding in patients with atrial fibrillation, ${ }^{2}$ and one which adversely affects prognosis (as would be expected, given the grim prognosis of heart failure per se). ${ }^{8}$

\section{Pathophysiological aspects}

The similarity of the epidemiological profiles of heart failure and atrial fibrillation and their frequent coexistence can readily be explained by considering the risk factors of either disorder. The importance of old age has already been mentioned, and the significance of ischaemic heart disease, hypertension, and valve disease is well established. ${ }^{29}$ Finally, specific factors such as diabetes mellitus and left ventricular hypertrophy also prognosticate the development of both heart failure and atrial fibrillation. There is also evidence of a causal relation between the two disorders.

\section{HEART FAILURE AS A CAUSE OF ATRIAL \\ FIBRILLATION}

Heart failure is an established predisposing condition for the development of atrial fibrillation. ${ }^{29}$ In fact, in the Framingham Study heart failure was the most powerful independent precursor of atrial fibrillation, with a relative risk of approximately sixfold. Interestingly, in another report from the Framingham Study even asymptomatic left ventricular dysfunction was found to be predictive of atrial fibrillation. ${ }^{10}$ It has also been shown that heart failure increases the likelihood of recurrence of atrial fibrillation after electrical cardioversion to sinus rhythm. ${ }^{11}$ Whereas the empirical evidence that heart failure may cause atrial fibrillation is irrefutable, the underlying pathophysiological mechanism is only partly understood. "Mechano-electrical feedback" at the atrial level presumably plays an important

Table 2 Studies on the effect of His bundle ablation on left ventricular function in selected patients with atrial fibrillation or flutter

\begin{tabular}{|c|c|c|c|c|}
\hline Reference & $\begin{array}{l}\text { Total } \\
\text { no of } \\
\text { patients }\end{array}$ & $\begin{array}{l}\text { No of } \\
\text { patients } \\
\text { with } E F<50 \% \\
\text { or } F S<27 \%\end{array}$ & $\begin{array}{l}\text { LV function } \\
\text { before } \\
\text { His bundle } \\
\text { ablation (\%)* }\end{array}$ & $\begin{array}{l}\text { LV function } \\
\text { after } \\
\text { His bundle } \\
\text { ablation (\%)* }\end{array}$ \\
\hline Rosenqvist et al ${ }^{22}$ & 5 & 5 & EF:27 & AF:45 \\
\hline Heinz et al ${ }^{23}$ & 10 & 5 & $\overline{F S}: 21$ & $\mathrm{ES}: 31$ \\
\hline Rodriguez et $a l^{24}$ & 30 & 12 & $E F: 43$ & $\mathrm{EF}: 54$ \\
\hline Twidale et al $^{25}$ & 14 & 10 & EF:42 & EF:47 \\
\hline Brignole $e t a l^{26}$ & 23 & 9 & FS:23 & FS:31 \\
\hline Edner $e t a l^{27}$ & 29 & 14 & EF:32 & $\mathrm{EF}: 45$ \\
\hline
\end{tabular}

$\star$ Data pertain only to the subgroup of patients with depressed left ventricular function befor His bundle ablation (except the study of Twidale $e t$ al in which the effect was not specified according to the two subgroups): no significant changes were observed after His bundle ablation in the subgroup of patients with preserved left ventricular function.

$\mathrm{EF}$, ejection fraction; FS, fractional shortening; LV, left ventricular. role. As a result of increased cardiac loading due to heart failure, the atria stretch, which in the experimental setting has been shown to produce profibrillatory changes in atrial conduction and refractoriness. ${ }^{12} 13$ In particular, the dispersion in atrial refractoriness increased secondarily to acute atrial loading, which was associated with enhanced inducibility of atrial fibrillation. These findings in animals have been confirmed in humans, acute changes in atrial load similarly affecting atrial electrophysiological properties. ${ }^{14}$ In addition to these acute, transient effects of atrial loading, it may be surmised that sustained atrial overload in the setting of chronic heart failure causes structural atrial enlargement that in turn would strongly facilitate atrial fibrillation. Supporting this possibility, we found that left atrial volume in a group of atrial fibrillation patients with overt heart failure was larger than in randomly selected atrial fibrillation patients, other factors known to affect left atrial volume being comparable; mean left atrial volume was $86 \mathrm{ml}$ and $74 \mathrm{ml}$, respectively. ${ }^{1516}$ Secondly, it may be hypothesised that atrial fibrillation in the setting of heart failure is also promoted by associated neurohumoral activation. In particular, activation of the sympathetic nervous system might facilitate the onset of atrial fibrillation by directly modifying atrial electrophysiological properties, thereby promoting atrial ectopy necessary for initiation of atrial fibrillation. ${ }^{17} 18$ Furthermore, elevated catecholamine and angiotensin II levels produce structural changes in the myocardium (myocyte hypertrophy, collagen accumulation, fibrosis), which in turn may promote dysrhythmias, ${ }^{19}$ presumably including atrial fibrillation. Underscoring the importance of sympathetic activation, Borzak et al have demonstrated in a dog model of heart failure that the propensity for development of atrial fibrillation was strongly related to the concentration of plasma noradrenaline. ${ }^{20}$ In that study development of atrial fibrillation was not predicted by any measure of left ventricular performance, but exclusively by plasma noradrenaline. Finally, in a recent study we found that plasma noradrenaline concentration before electrical cardioversion tended to be higher in heart failure patients with subsequent recurrence of atrial fibrillation (after cardioversion) than in patients who maintained sinus rhythm. ${ }^{15}$

\section{ATRIAL FIBRILLATION AS A CAUSE OF HEART} FAILURE

Besides the fact that heart failure can cause atrial fibrillation, atrial fibrillation may also cause heart failure. Among clinicians it is common knowledge that acute atrial fibrillation may precipitate overt heart failure in the setting of asymptomatic left ventricular dysfunction. Impaired diastolic filling secondary to loss of atrial systolic function and to rapid, irregular ventricular rhythm plays a crucial role in this connection. If ventricular rate is inadequately controlled, atrial fibrillation may also depress systolic function, which may eventually result in severe heart failure, even 
without prior structural heart disease. ${ }^{21-27}$ This phenomenon has been termed "tachycardiomyopathy". The clinical evidence for this type of cardiomyopathy stems from the observation that left ventricular function often markedly improves after alleviation of high ventricular rate. Radiofrequency ablation of the His bundle may be used (table 2).

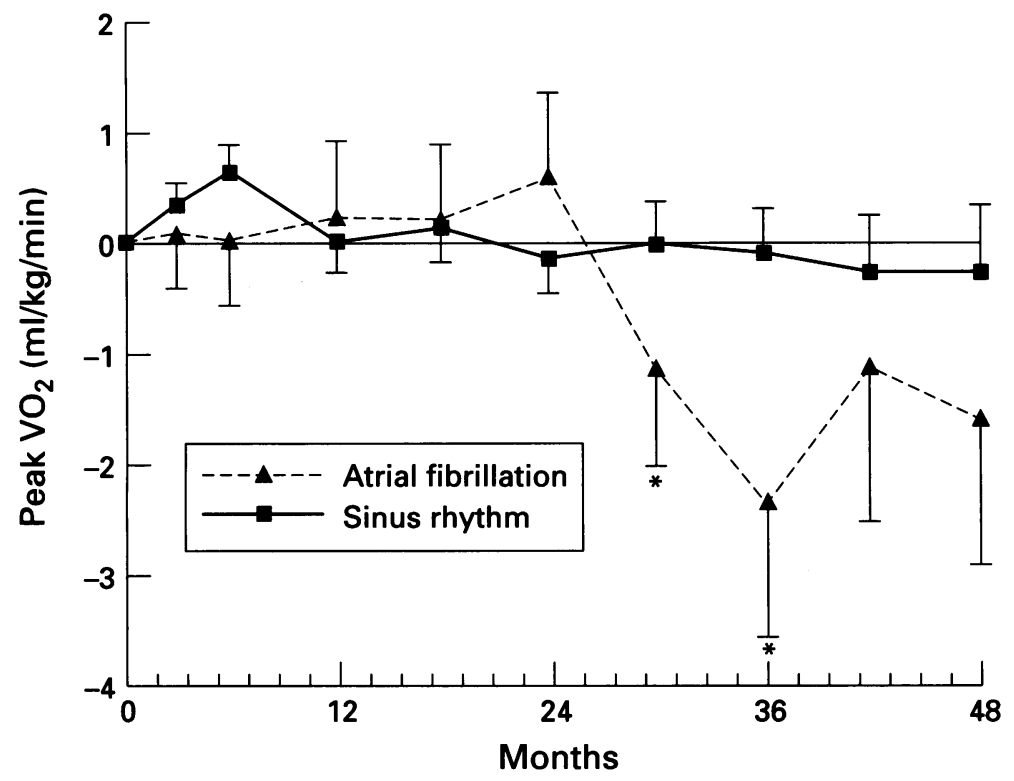

$\begin{array}{lcccc}\text { Atrial fibrillation } & \mathrm{n}=61 & \mathrm{n}=38 & \mathrm{n}=23 & \mathrm{n}=15 \\ \text { Sinus rhythm } & \mathrm{n}=365 & \mathrm{n}=246 & \mathrm{n}=141 & \mathrm{n}=70\end{array}$

Figure 1 Change in peak oxygen consumption during follow up in the V-HeFT II study comparing patients with sinus rhythm and atrial fibrillation. After two years patients with atrial fibrillation showed a significant decline in peak oxygen consumption, whereas peak oxygen consumption in patients with sinus rhythm remained unchanged. (Reproduced from Carson et al. The influence of atrial fibrillation on prognosis in mild to moderate heart failure. The V-HeFT Studies. Circulation 1993;87(suppl VI):102-10. With permission of the American Heart Association).

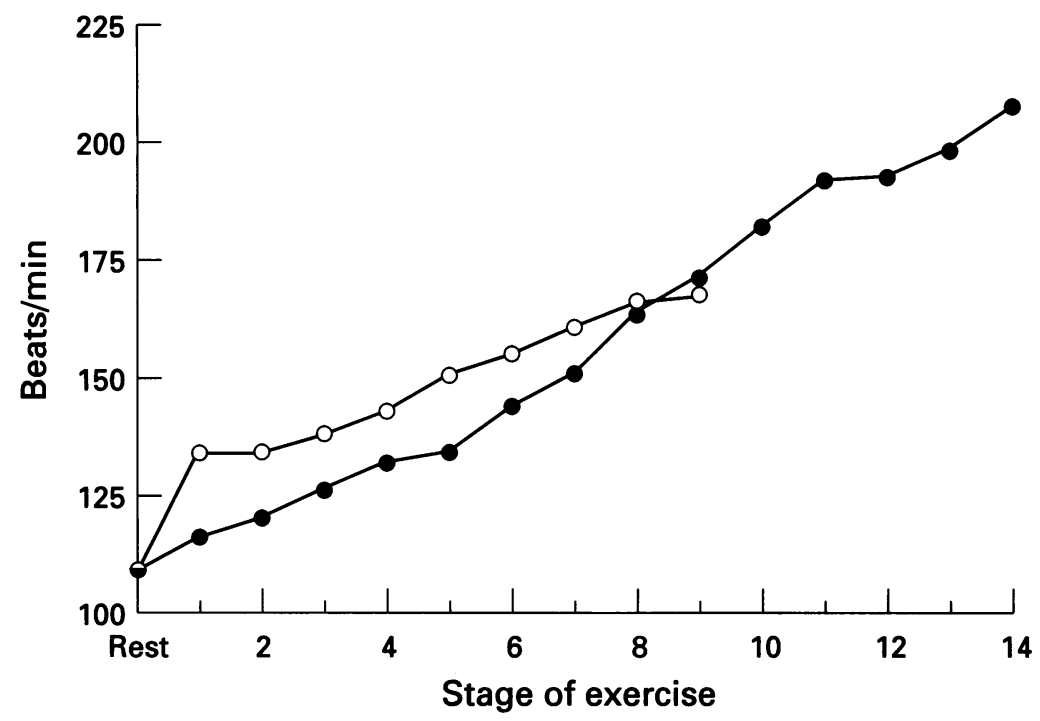

Figure 2 Relation between stage of exercise and heart rate in 21 patients with chronic atrial fibrillation with peak oxygen consumption $\leqslant 20 \mathrm{ml} / \mathrm{min} / \mathrm{kg}$ (open circles) and 24 patients with peak oxygen consumption $>20 \mathrm{ml} / \mathrm{min} / \mathrm{kg}$ (closed circles). All patients were on digoxin, calcium antagonists or both for control of ventricular rate; no patients used antiadrenergic agents, including angiotensin converting enzyme inhibitors or $\beta$ blockers. Patients with preserved functional capacity (peak oxygen consumption $>20 \mathrm{ml} / \mathrm{min} / \mathrm{kg}$ ) showed a gradual increase in heart rate as a function of exercise. In contrast, though heart rate at rest was reasonably well controlled, in patients with impaired functional capacity (peak oxygen consumption $\leqslant 20 \mathrm{ml} / \mathrm{min} / \mathrm{kg}$ ) a marked heart rate increase was observed at low levels of exercise compared with patients with preserved functional capacity. In addition, maximal heart rate was attenuated. (Reproduced from Van Den Berg et al. Chronotropic response to exercise in patients with atrial fibrillation: relation to functional state. Br Heart J 1993;70:150-3. With permission of BMF Publishing Group).
Numerous animal studies support the concept of tachycardiomyopathy; in fact, rapid cardiac pacing was already an established means of producing experimental heart failure long before appreciation of the concept by clinicians became widespread. In addition to the aforementioned (sub)acute effects of atrial fibrillation, there is also evidence of a more subtle, insidious long term deleterious effect on left ventricular function. Unlike straightforward tachycardiomyopathy this would affect many patients with atrial fibrillation, even when ventricular rate is adequately controlled. Thus, in the V-HeFT II study, ${ }^{6}$ patients with atrial fibrillation showed a significant decline in peak oxygen consumption compared with patients in sinus rhythm starting after two years of follow up (fig 1). Recently, we observed a comparable phenomenon in a twoyear follow up study after electrical cardioversion. ${ }^{28}$ Despite similar clinical characteristics at baseline, patients who maintained sinus rhythm showed a gradual, sustained increase in peak oxygen consumption, whereas patients with recurrence of atrial fibrillation demonstrated a clear decrease after two years. Furthermore, it was shown that electrical cardioversion of atrial fibrillation was associated with a discrepancy in the time course of recovery of atrial systole and ventricular function. ${ }^{29}$ Although the atrial contribution to ventricular filling normalised within one week after cardioversion, left ventricular ejection fraction continued to increase beyond that time, reaching peak values after one month. It was noteworthy that the increase in peak oxygen consumption was parallel to the increase in ejection fraction.

Taken together, these observations suggest the presence of a subtle form of cardiomyopathy, inherent to chronic atrial fibrillation. The underlying mechanism is as yet unknown; however, two factors might be involved. First, "concealed" tachycardiomyopathy; although ventricular rate at rest may be well controlled ( $<100$ beats $/ \mathrm{min}$ ), patients with atrial fibrillation often exhibit disproportionately high rates ( $>120$ beats $/ \mathrm{min}$ ) during minor exercise (normal daily activities). Patients in whom the left ventricular function is already impaired are particularly likely to exhibit such responses, due to excessive sympathetic activation early during exercise (fig 2). ${ }^{153031}$ It is conceivable that this has long term deleterious effects on left ventricular systolic function, considering the fact that tachycardiomyopathy may develop in patients with paroxysmal atrial fibrillation and with ventricular rates as "low" as 120 beats/min or even lower. ${ }^{21-27}$

Second, depletion of atrial natriuretic peptide may play a role. Whereas in the acute stage atrial fibrillatory activity (irrespective of concomitant haemodynamic changes) may enhance atrial natriuretic peptide secretion, ${ }^{32}$ longstanding atrial fibrillation is associated with atrial natriuretic peptide depletion, resulting from extensive atrophy and fibrosis of the atria. This may result in complete "endocrinological silence". ${ }^{33}$ We recently found an inverse relation between plasma 
atrial natriuretic peptide and the duration of atrial fibrillation in patients with atrial fibrillation and concomitant heart failure (unpublished results). Although diminished atrial natriuretic peptide production does not directly affect left ventricular systolic function, it may contribute to eventual haemodynamic deterioration - that is, heart failure.

\section{Clinical management}

Traditionally, many clinicians rely on cardioversion (either chemical or electrical) as a firstline therapeutic measure in patients with atrial fibrillation, irrespective of concomitant heart failure. This approach is supported by the consistent finding that the duration of atrial fibrillation is a prime determinant of the likelihood of maintenance of sinus rhythm after cardioversion: the longer the duration of atrial fibrillation the higher the risk of relapse. ${ }^{11}$ However, irrespective of the duration of atrial fibrillation, it is important that hypertension, myocardial ischaemia, thyrotoxicosis, and heart failure should be treated before attempting cardioversion. In addition, it should be realised that the prophylactic use of antiarrhythmic drugs is hazardous in cases of heart failure; while the efficacy in maintaining sinus rhythm after cardioversion is low, these agents may actually increase mortality because of negative inotropic and proarrhythmic effects. ${ }^{35}$ Hence, except in cases of emergency (haemodynamic shock), cardioversion is generally not appropriate as a first-line measure in patients presenting with heart failure and atrial fibrillation; treatment should instead focus on heart failure.

We have shown recently that treatment with an angiotensin converting enzyme inhibitor is useful. ${ }^{15} \mathrm{Also}$, adequate control of ventricular rate is crucial. Classically, digoxin is widely used but it is often necessary to add another (intravenous) agent - $a$ blocker or a calcium antagonist. Diltiazem has been shown to be generally safe in the setting of acute heart failure and atrial fibrillation, and to control ventricular rate rapidly and effectively. ${ }^{36}$ Alternatively, a case can be made for the $\beta$ blocker esmolol. ${ }^{37}$ Due to its ultrashort halflife (nine minutes) this agent is theoretically well suited for the critical care setting, including acute heart failure and atrial fibrillation. Rate control with digoxin as monotherapy is often insufficient beyond the acute stage; although, by virtue of its vagomimetic effect, it may control ventricular rate reasonably well at rest, rate control during exercise, including low levels of exercise, is usually inadequate. Hence, as in the acute stage, it is often necessary to add another agent. The efficacy of calcium antagonists and $\beta$ blockers in this connection is unknown; previous studies have included mainly atrial fibrillation patients with (near) normal cardiac function, and have focused on heart rate at maximal exercise rather than at lower levels of exercise. Furthermore, the duration of treatment in most studies was relatively short (two to three weeks). These considerations, together with those mentioned earlier, provide a rationale for adding a $\beta$ blocker rather than a calcium antagonist to digoxin. The dose will probably have to be relatively low to allow for a sufficient rise in heart rate during heavy exercise, and long term treatment is needed before a beneficial effect can be expected; however, anecdotal experience suggests that patients may indeed benefit early. ${ }^{38}$ Finally, if the patient proves drug refractory despite the use of a combination of negative inotropic agents, His bundle ablation is an option.

1 Ho KKL, Anderson KM, Kannel WB, Grossman W, Levy D. Survival after the onset of congestive heart failure. Circulation 1993;88:107-15.

2 Kannel WB, Abbott RD, Savage DD, McNamara PM. Epidemiologic features of chronic atrial fibrillation. The Framingham Study. N Engl ₹ Med 1982;306:1018-22.

3 Likoff MJ, Chandler SL, Kay KR. Clinical determinants of mortality in chronic congestive heart failure secondary to idiopathic dilated or to ischemic cardiomyopathy. $A m \mathcal{F}$ Cardiol 1987;59:634-8.

4 Keogh AM, Baron DW, Hickie JB. Prognostic guides in patients with idiopathic or ischemic dilated cardiomopathy 65:903-8.

5 Middlekauf HR, Stevenson WG, Stevenson LW. Prognostic significance of atrial fibrillation in advanced heart failure. A study of 390 patients. Circulation 1991;84: 40-8.

6 Carson PE, Johnson GR, Dunkman WB, Fletcher RD, Farell L, Cohn JN, for the V-HeFT VA Cooperative Farell L, Cohn JN, for the V-HeFT VA Cooperative prognosis in mild to moderate heart failure. The V-HeFT prognosis in mild to moderate heart failure. The
Studies. Circulation 1993;87(suppl VI):102-10.

7 Hofmann T, Meinertz T, Kasper W, Geibel A, Zehender $\mathrm{M}$, Hohnloser $\mathrm{S}$, et al. Mode of death in idiopathic dilated cardiomyopathy: a multivariate analysis of prognostic determinants. Am Heart $\mathcal{F}$ 1988;116:1455-63.

8 Van Gelder IC, Crijns HJGM, Tieleman RG, Hillege HJ, Gosselink ATM, Lie KI. Mortality in patients with atria fibrillation is related to the severity of the underlying disease and not to the arrhythmia [abstract]. Circulation 1994;90(suppl I):541.

9 Benjamin EJ, Levy D, Vaziri SM, D'Agostino RB, Belanger AJ, Wolf PA. Independent risk factors for atrial fibrillation in a population-based cohort. The Framingham Heart Study. $\mathfrak{F} A M A$ 1994;271:840-4.

10 Vaziri SM, Larson MG, Benjamin EJ, Levy D. Echocardiographic predictors of nonrheumatic atrial fibrillation. The Framingham Heart Study. Circulation 1994; 89:724-30.

11 Van Gelder IC, Crijns HJGM, Van Gilst WH, Verwer R, Lie KI. Prediction of uneventful cardioversion and maintenance of sinus rhythm from direct-current electrical tenance of sinus rhythm from direct-current electrical cardioversion of chronic

12 Solti F, Vescey T, Kékesi V, Juhàsz-Nagy A. The effect of atrial dilatation on the genesis of atrial arrhythmias. Cardiovasc Res 1989;23:882-6.

13 Isobe $F$, Schuessler RB, Mitsuno $M$, Nitta $T$, Cronin CS, Boineau JP, et al. High atrial pressure directly affects the dispersion of refractoriness and the inducibility of atria fibrillation [abstract]. Circulation 1993;88(suppl I):326.

14 Klein LS, Miles WM, Zipes DP. Effect of atrioventricula interval during pacing or reciprocating tachycardia on atrial size, pressure, and refractory period. Contractionexcitation feedback in the human atrium. Circulation 1990;82:60-8.

15 Van Den Berg MP, Crijns HJGM, Van Veldhuisen DJ, Griep N, De Kam PJ, Lie KI. Effects of lisinopril in patients with heart failure and chronic atrial fibrillation. $f$ pardiac Failure 1995;1:355-64.

16 Gosselink ATM, Crijns HJGM, Hamer HPM, Hillege HJ, Lie KI. Changes in left and right atrial size after cardioversion of atrial fibrillation: role of mitral valve disdioversion of atrial fibrillation: role of mitri
ease. $₹ \mathrm{Am}$ Coll Cardiol 1993;22:1666-72.

17 Coumel P. Neural aspects of paroxysmal atrial fibrillation. In: Falk RH, Podrid PJ, eds. Atrial fibrillation. Mechanisms and management. New York: Raven Press, Mechanisms and

18 Van Den Berg MP, Venema AW, Crijns HJGM, Heesen WF, Brouwer J, Lie KI. Clinical and electrocardiographic correlates of exercise-induced atrial fibrillation: a casecontrol study. Am $\mathcal{f}$ Noninvas Cardiol 1994;8:146-50

19 Pinto YM, Buikema JH, Van Gilst WH. Hyperactive tissue renin-angiotensin systems in cardiovascular dysfunction: experimental evidence and clinical hypotheses. Clin Exp Hypertens 1995;17:441-68.

20 Borzak S, Goldstein S, Sabbah HN. Hemodynamic and neurohumoral predictors of the development of atrial fibrillation in dogs with chronic heart failure [abstract] Circulation 1993;88(suppl I): 18 .

21 Grogan M, Smith HC, Gersh BJ, Wood DL. Left ventricular dysfunction in patients initially believed to have idiopathic dilated cardiomyopathy. Am $\mathcal{F}$ Cardiol 1992;69: 1570-3. 
22 Rosenqvist M, Lee MA, Moulinier L, Springer MJ, Abbott $\mathrm{JA}, \mathrm{Wu} \mathrm{J}$, et al. Long-term follow-up of patients after transcatheter direct current ablation of the atrioventricular transcatheter direct current ablation of the atriove

23 Heinz G, Siostrzonek P, Kreiner G, Gössinger H. Improvement in left ventricular systolic function after successful radiofrequency $\mathrm{His}$ bundle ablation for drug refractory radiofrequency His bundle ablation for drug refractory,
chronic atrial fibrillation and recurrent atrial flutter. $A m \mathcal{g}$ chronic atrial fibrillation and

24 Rodriguez LM, Smeets JLRM, Xie B, De Chilou C, Cherieux E, Pieters F, et al. Improvement in left ventricular function by ablation of atrioventricular nodal conduction in selected patients with lone atrial fibrillation. $A m \mathcal{F}$ Cardiol 1993;72:1137-41.

25 Twidale N, Sutton K, Bartlett L, Dooley A, Winstanley S Heddle W, et al. Effects on cardiac performance of atrioventricular node catheter ablation using radiofrequency current for drug-refractory atrial arrhythmias. Pacing Clin Electrophysiol 1993;16:1275-84.

26 Brignole M, Gianfranchi L, Menozzi C, Bottoni N, Bollin $R$, Lolli $G$, et al. Influence of atrioventricular junction radiofrequency ablation in patients with chronic atrial fibrillation and flutter on quality of life and cardiac performance. Am ₹ Cardiol 1994;74:242-6.

27 Edner M, Caidahl K, Bergfeldt L, Darpö B, Edvardsson N, Rosenqvist M. Prospective study of left ventricular function after radiofrequency ablation of atrioventricular junction in patients with atrial fibrillation. Br Heart $f$ junction in patien.

28 Gosselink ATM, Bijlsma EB, Landsman MJL, Crijns HJGM, Lie KI. Long-term effect of cardioversion on peak oxygen consumption in chronic atrial fibrillation. Eur Heart $\mathcal{F}$ 1994; 15:1368-72.

29 Van Gelder IC, Crijns HJGM, Blanksma PK, Landsma MJL, Posma JL, Van Den Berg MP, et al. Time course of hemodynamic changes and improvement of exercise tolerance after cardioversion of chronic atrial fibrillation unassociated with cardiac valve disease. Am $f$ Cardiol 1993;72:560-6.

30 Francis GS. Hemodynamic and neurohumoral responses to dynamic exercise: normal subjects versus patients with heart disease. Circulation 1987;76(suppl VI):12-17.

31 Van Den Berg MP, Crijns HJGM, Gosselink ATM, Van Den Broek SAJ, Hillege HJ, Van Veldhuisen DJ, et al.
Chronotropic response to exercise in patients with atrial Chronotropic response to exercise in patients with atrial f0:150-3.

32 Schiebinger RJ, Linden J. Effect of contraction frequency on atrial natriuretic peptide secretion. Am F Physiol 1986; 251:H1095-9.

33 Seino Y, Shimai S, Ibuki C, Itoh K, Takano T, Hayakawa $H$. Disturbed secretion of atrial natriuretic peptide in patients with persistent atrial standstill. $\mathcal{F} \mathrm{Am}$ Coll Cardiol 1991;18:459-63.

34 Sanfilipo AJ, Abascal VM, Sheehan M, Oertel LB, Harrigan P, Hughes RA, et al. Atrial enlargement as a consequence of atrial fibrillation. A prospective echocardiographic study Circulation 1990;82:792-7.

35 Flaker GC, Blackshear IL, McBride R, Kronmal R, Halperin JL, Hart RG, on behalf of the Stroke Prevention in Atrial Fibrillation Investigators. Antiarrhythmic drug therapy and cardiac mortality in atrial fibrillation. $\mathcal{f} \mathrm{Am}$ therapy and cardial 1992;20:527-32.

36 Goldenberg IF, Lewis WR, Dias VC, Heywood JT, Pedersen WR. Intravenous diltiazem for the treatment of patients with atrial fibrillation or flutter and moderate to patients with atrial fibrillation or flutter and moderate to severe

37 Platia EV, Michelson EL, Porterfield JK, Das G. Esmolol versus verapamil in the acute treatment of atrial fibrillation or atrial flutter. Am $\mathcal{F}$ Cardiol 1989;63:925-9.

38 Van Den Berg MP, Van Veldhuisen DJ, Crijns HJGM, Lie KI. Reversion of tachycardiomyopathy after $\beta$-blocker [letter]. Lancet 1993;341:1667. 